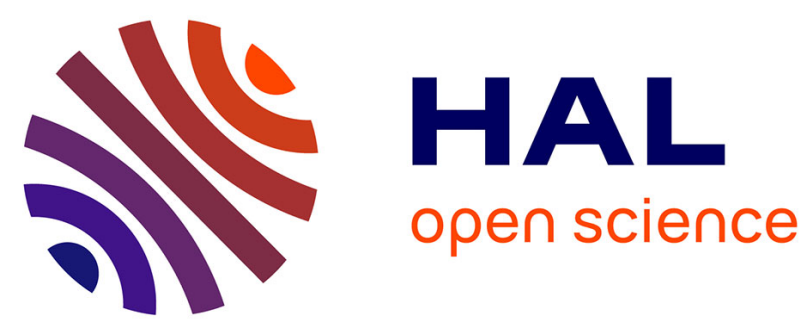

\title{
What do we really know about motor learning in children with Developmental Coordination Disorder?
}

Maëlle Biotteau, Yves Chaix, Jean-Michel Albaret

\section{To cite this version:}

Maëlle Biotteau, Yves Chaix, Jean-Michel Albaret. What do we really know about motor learning in children with Developmental Coordination Disorder?. Current Developmental Disorders Reports, 2016, vol. 3 ( $\mathrm{n}^{\circ} 2$ ), pp. 152-160. 10.1007/s40474-016-0084-8 . hal-01338285

\section{HAL Id: hal-01338285 \\ https://hal.science/hal-01338285}

Submitted on 28 Jun 2016

HAL is a multi-disciplinary open access archive for the deposit and dissemination of scientific research documents, whether they are published or not. The documents may come from teaching and research institutions in France or abroad, or from public or private research centers.
L'archive ouverte pluridisciplinaire $\mathbf{H A L}$, est destinée au dépôt et à la diffusion de documents scientifiques de niveau recherche, publiés ou non, émanant des établissements d'enseignement et de recherche français ou étrangers, des laboratoires publics ou privés. 


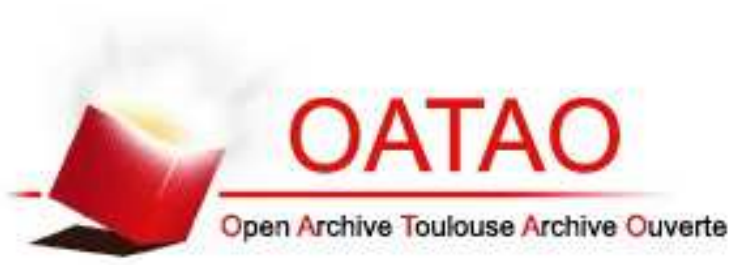

\section{Open Archive TOULOUSE Archive Ouverte (OATAO)}

OATAO is an open access repository that collects the work of Toulouse researchers and makes it freely available over the web where possible.

This is an author-deposited version published in: http://oatao.univ-toulouse.fr/ Eprints ID : 15935

To link to this article : DOI:10.1007/s40474-016-0084-8

URL : http://dx.doi.org/10.1007/s40474-016-0084-8

\section{To cite this version :}

Biotteau, Maëlle and Chaix, Yves and Albaret, Jean-Michel What do we really know about motor learning in children with Developmental Coordination Disorder? (2016) Current Developmental Disorders Reports, vol. 3 ( $\left.\mathrm{n}^{\circ} 2\right)$. pp. 152-160. ISSN 2196-2987

Any correspondence concerning this service should be sent to the repository administrator: staff-oatao@listes-diff.inp-toulouse.fr 


\title{
What Do We Really Know About Motor Learning in Children with Developmental Coordination Disorder?
}

\author{
Maëlle Biotteau $^{1} \cdot$ Yves Chaix $^{1,2} \cdot$ Jean-Michel Albaret $^{1}$
}

\begin{abstract}
There is a general consensus that developmental coordination disorder (DCD) is characterized by impaired motor learning skills. However, actual studies of motor learning in DCD are scarce and, above all, inconsistent. The aims of the present study were therefore to explore the presumed presence of a motor learning deficit among individuals with DCD and to provide a synopsis of the current literature on motor learning in DCD. We begin by defining DCD (etiology, neuropsychology, and brain bases), motor learning (measurement of learning, methods for promoting skill acquisition, scheduling, practice, retention, and feedback) and, of course, the link between the two, focusing on the issue of a possible motor learning deficit in DCD. We then discuss dominant hypotheses and suggest directions for future research in this domain, in the light of research conducted thus far. Particular attention is paid throughout to guide the choice of intervention approaches.
\end{abstract}

Keywords Developmental coordination disorder (DCD) . Motor learning · Procedural learning · Sequence learning · Sensorimotor adaptation $\cdot$ Review

This article is part of the Topical Collection on Disorders of Motor

Maëlle Biotteau

maelle.biotteau@inserm.fr

Yves Chaix

chaix.y@chu-toulouse.fr

Jean-Michel Albaret

jean-michel.albaret@univ-tlse3.fr

1 Toulouse NeuroImaging Center, Université de Toulouse, Inserm, UPS, Toulouse, France

2 Children's Hospital, Toulouse-Purpan University Hospital, Place du Dr Baylac, 31059 Toulouse, Cedex 9, France

\section{Introduction}

Children with developmental coordination disorder (hereafter DCD) show a markedly impaired ability to learn ageappropriate motor skills in the absence of any general medical condition or neurological or intellectual dysfunction [1]. In daily life and leisure activities, these children exhibit motor difficulties, manifested as clumsiness, as well as slow and inaccurate performance of both gross and fine motor skills [2]. They perform more poorly and less accurately than controls on manual dexterity tasks such as drawing and handwriting, resulting in some difficulties in the school environment [3]. All these factors play an important role in participation and psychosocial function difficulties.

In summary, affected individuals typically have problems acquiring and performing daily activities that require the learning of fundamental motor skills (running, hopping, or catching or throwing a ball) [4]. The onset of symptoms takes place in the early developmental period, and up to $6 \%$ of schoolchildren are thought to be affected by DCD [1]. Without appropriate intervention during childhood, these deficiencies can last well into adolescence and adulthood [5].

The mechanisms underlying this disorder are still largely unknown. It has been suggested that DCD may be related to central nervous system dysfunction. Structural or functional differences in the brain have been postulated, showing that DCD could be the result of diffuse brain dysfunction, as well as abnormalities in specific areas of the brain (especially parietal and dorsolateral prefrontal areas, as well as cerebellum) [6].

Nonetheless, although poor motor skills are a defining feature of DCD, the level of motor learning in these children is still not understood sufficiently clearly. In this context, we decided to focus on the motor learning aspect of DCD and ask the question of what we really know about motor learning in DCD. 


\section{Motor Learning Deficits: a Complex Notion}

\section{How Is Motor Learning Defined?}

Motor learning has been defined as "a set of processes associated with practice or experience leading to relatively permanent changes in the capability for skilled performance" ([7], p. 178).

Motor skill learning involves two distinct learning processes, explicit and implicit learning, with implicit learning referring to the learning of complex information in an incidental manner, without awareness of what has been learned, and explicit learning referring to learning where the instructor clearly outlines the learning goals and offers unambiguous explanations. Although these two processes appear to take place in different learning stages and different learning situations, they have recently been shown to overlap during skill learning.

\section{How Does Motor Learning Take Place?}

Cognitive learning is characterized by two phases (slow and fast, each involving distinct processes), that are related with earlier notions of cognitive, associative, and consolidation stages of learning [8]. From a behavioral point of view, the incremental acquisition of motor skills is known to take place in two distinct and successive stages [9]. During the first phase (fast learning), rapid and considerable improvement in performance can be observed within a single training session. During the second phase (slow learning), further gains can gradually be observed (consolidation then stabilization of performance steps) across several training sessions until automatization is achieved. It should be noted that once overlearned, a motor skill can be readily retrieved and performed reasonably well, without fatigue or conscious control. Transfer of the skill to a new situation is then possible [10].

Feedback appears to be a crucial element of success in both stages of learning. Feedback refers to the information an individual receives about the performance of a motor task while it is underway or after completion of the movement. It comes in two forms: information about the movement gained through the interpretation of sensory experiences (intrinsic feedback) and external information provided during or after the movement (extrinsic or augmented feedback) [11]. During the learning process, a changing balance of feedback-based and feedforward mechanisms appears facilitating speed, flexibility, and adaptability through a predictive control [12].

\section{Sequence Learning Versus Motor Adaptation}

Motor learning has been divided into two broad experimental categories: sequence learning and motor (sensorimotor or perceptuomotor) adaptation [9]. Sequence learning refers to an ability to combine isolated movements into a single smooth and coherent action. To investigate sequence learning, the most widely used paradigm is the serial reaction time task (SRTT): stimuli are displayed successively at different locations in a repeating sequence, and participants respond to each one by pressing a corresponding key, with a progressive improvement of reaction time and number of errors over time [13].

Motor adaptation refers to the learning of new associations between vision and hand movements and consists of a change in motor performance driven by a perturbation (e.g., a change in the environment). Individuals modify their movements to adjust to changes in either sensory input or motor output characteristics. Hence, the goal of adaptation is to reduce systematic errors induced by the perturbation. To investigate motor adaptation ability, two broad types of sensorimotor adaptation paradigms have been used: kinematic adaptation, where the sensory feedback of movements is distorted through the use of laterally displacing prisms, computer programs, or a mirror tracing paradigm $[14,15]$; and dynamic adaptation, where, for example, the anticipated proprioception is altered during reaching movements to a series of targets while holding the handle of the robot with an opposing force produced by the robot [16]. Both can be described as explicit, insofar as participants know from the outset that they need to improve their performance.

\section{Measurement of Motor Learning}

Motor learning is measured by analyzing performance in three distinct ways: acquisition, retention, and transfer of skills [11]. Here, the term acquisition refers to the initial practice or performance of a new skill; retention is the ability to demonstrate attainment of the goal (or an improvement of some aspect), following a short or long interval during which the task is not practiced; and transfer requires the performance of a task requiring a similar movement but nonetheless different from the original task. The relatively permanent changes over time that constitute the essence of learning necessitate also follow-up studies.

We should specify that acceptable performance of a motor skill within a single session or series of sessions does not in itself demonstrate that the skill has been learned. A multilevel improvement must be observed, in speed, accuracy, and/or a change in movement synergy and kinematics.

\section{Motor Learning in DCD}

\section{Is DCD a Motor Learning Deficit? A Confusion Maintained by Researchers}

Clinically, children with DCD have difficulty learning and automatizing daily motor activities (e.g., handwriting and getting dressed continue to require particular attention even after a great deal of practice). Affected children are characteristically slow in 
learning motor routines and also find learning new motor skills or unfamiliar motor tasks a significant challenge [17].

As children with DCD have difficulty learning a number of motor skills in daily life (that typically developing children can effortlessly acquire), experiencing both motor difficulties and learning impairments, DCD is often referred to as a motor learning deficit [18] or as a procedural learning disorder [19]. Many articles on DCD have therefore presented this disorder as a motor learning deficit over the years, stating, for instance, that "children with developmental coordination disorder (DCD) have a motor learning disability" [20]) or, more recently, "developmental coordination disorder (DCD) is classified as a heterogeneous disorder of motor learning and functioning" [21], and even that "DCD is characterized by poor learning and coordination of motor skills" [22]. While these definitions may be relevant, it should be noted that reduced motor learning capacity is just an implicit assumption under the different editions of the Diagnostic and Statistical Manual of Mental Disorders (criteria A of the DSM-5 mentions only "the acquisition (...) of coordinated motor skills") [1]. We therefore run the risk of confusion and of misunderstanding the characteristics of DCD. For while motor skill deficits in DCD have been well documented, empirical evidence of a motor skill learning deficit is still sparse. To date, therefore, motor learning in DCD remains poorly studied and understood.

\section{What Do We Actually Know About Motor Learning in DCD?}

As described above, to study the mechanisms and time course of learning, we have at our disposal experimental paradigms that allow us to measure either the incremental acquisition of movements to construct well-executed behavior (motor sequence learning) or participants' ability to compensate for environmental changes (motor adaptation). Despite the formal recognition of motor learning difficulties in daily living, very few studies (Table 1 for an overview) have explored motor learning in DCD using tasks like these, and fewer still have investigated both stages of motor skill learning (initial training session, then consolidation and stabilization, automatization, and/or transfer).

Especially, only three studies have explored motor sequence learning in children with DCD using the SRTT [13], and all of them restricted themselves to the first stage of motor skill learning. Although one study [37] reported impairment in children with DCD, the other two found preserved implicit learning abilities [23, 24]. However, as a complement to this question, it should be noted that the meta-analysis of Wilson et al. [12] upon the main motor control and cognitive deficits well-indicated a large effect size for procedural learning $\left(d_{\mathrm{w}}=1.50\right)$.

More studies have investigated motor adaptation tasks (e.g., [27-33]), but with contradictory results. When
Zwicker et al. [29] compared children with DCD and typically developing (TD) children performing a trail-tracing task using a joystick (task practiced in four 2-min blocks per day over 3 days), they observed poor motor learning in children with DCD (no change in tracing error from early practice to retention test). Using computer-manipulated adaptation paradigms (with adaptation to a novel visuomotor task and visual feedback), Kagerer et al. [27] also found poorer motor learning in children with DCD than in controls and further reported that their performances were more variable and they failed to adapt to the novel visual-motor relationship. Similarly, after carrying out a study featuring a prism adaptation task, Brookes et al. [26] concluded that children with DCD have an impaired rate of adaptation.

By contrast, using prism adaptation and throwing movements, Cantin et al. [25] demonstrated that children with DCD are able to learn and do not have an adaptation problem, even if their performances were more variable and less accurate than those of TD children. The same team also found that children with DCD were just as fast and as accurate as their peers on a simple visual-motor task [30]. Meanwhile, when Missiuna [31] administered a simple visual-motor task to children with DCD back in 1994, she observed a typical pattern of acquisition.

Discrepancies between results, whether for motor sequence learning or for motor adaptation, can be explained by methodological issues (sample size, age range, paradigm, etc.). In particular, here, we focus on the issues of task difficulty, implicit versus explicit teaching, and comorbidity.

The difficulty of the task can indeed change and impact the children's level of motor learning. Cantin et al. [30] found that children with DCD can learn a simple visual-motor task just as rapidly and accurately as their peers but are slower and less accurate when it comes to performing a more complex one. These results are in line with those of Candler and Meeuwsen [32], who detected a statistically significant interaction between task difficulty and implicit motor learning in children with DCD. This is more broadly in accordance with the challenge point model [38], which states that the impact of task difficulty on task performance and learning is influenced by skill level. Implicit or explicit teaching is therefore an important factor to consider. Although explicit motor teaching seems to be a major factor for effective motor learning in children with DCD (see all the studies on intervention strategies), research has also demonstrated that children with DCD are able to learn implicitly, albeit on an artificial paradigm [32] or in a more complex and natural context, such as serious gaming [39]. The last factor to take into consideration is obviously comorbidity. Comorbidity is commonly found in developmental disorders, and those associated with DCD could therefore potentially affect children's motor learning ability. Several authors have considered comorbidities in their inclusion/exclusion criteria, but others have not. This has led 


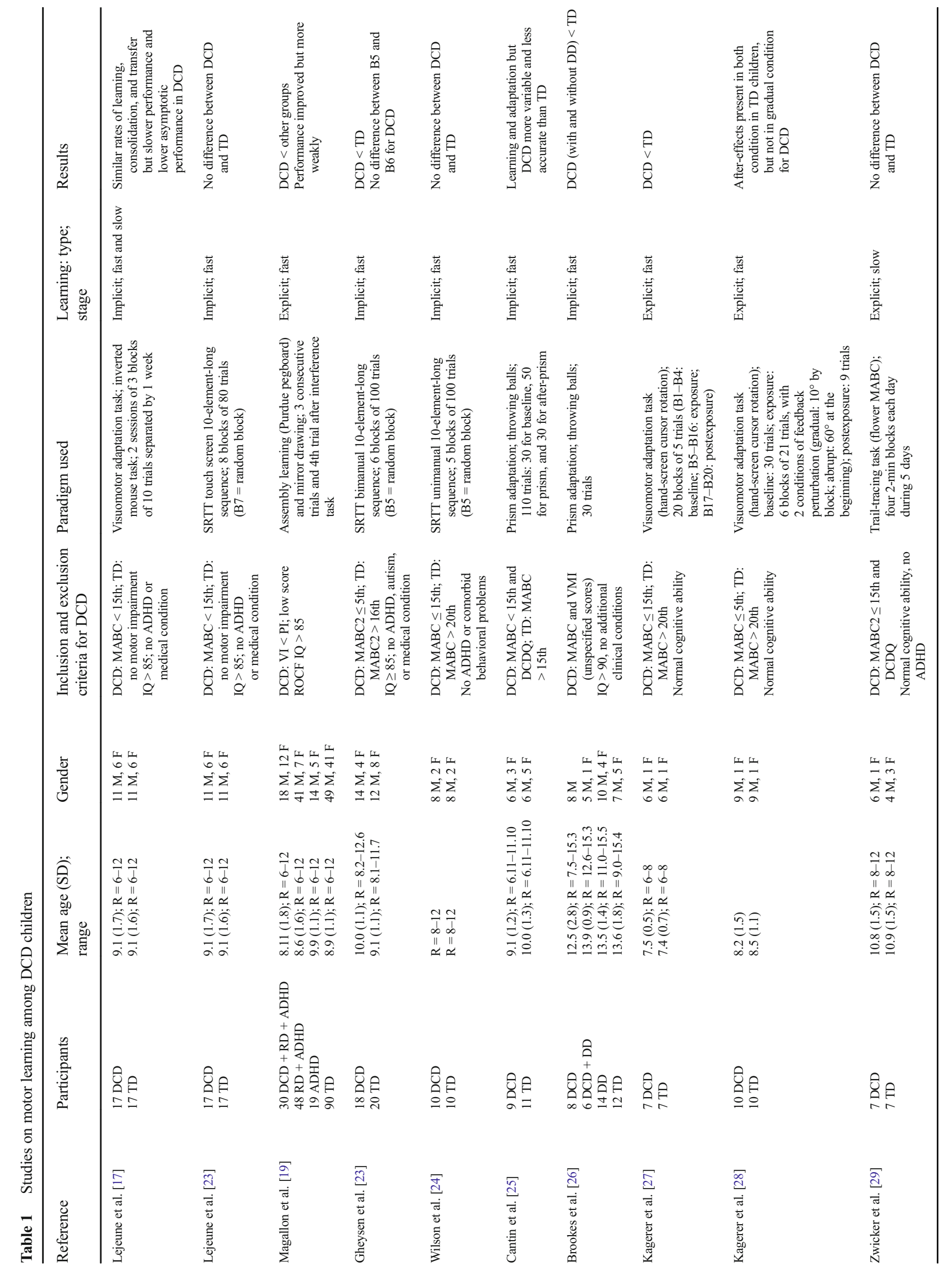




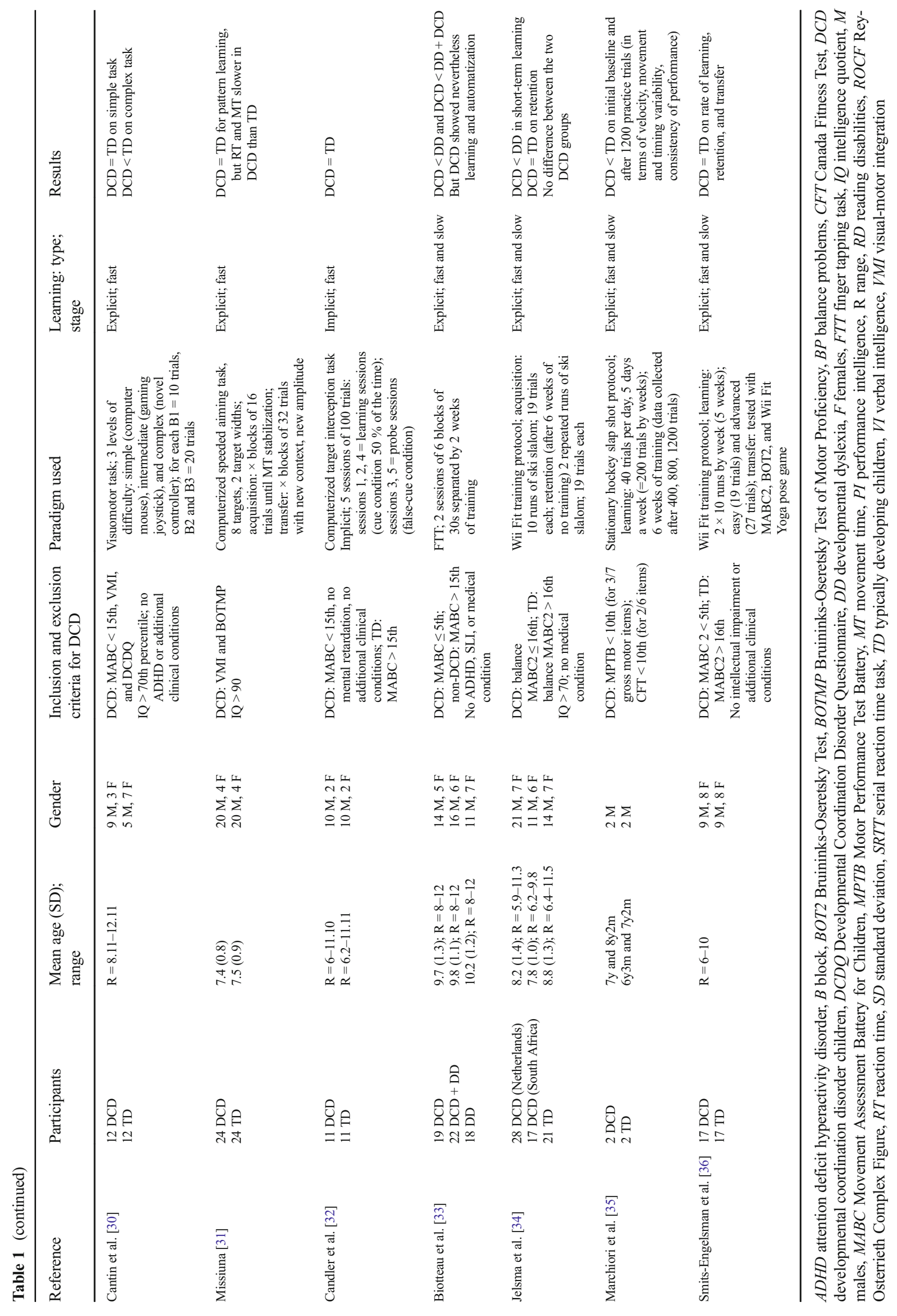


to very different samples: DCD with comorbid association, pure DCD, or undetermined/unknown (no investigation of comorbidity). Further studies regarding these specific points are required, in order to either control for comorbidity or to explore differences between comorbid groups. To date, only two studies have clearly tested the impact of comorbidity on motor learning ability $[19,33]$. Both have suggested that, even when DCD is associated with another disorder (developmental dyslexia, reading disabilities, or attention deficit hyperactivity disorder), children are able to improve their performances with repetition and to learn a motor task using repetition-based learning of procedures.

What is certain, however, is that if we want to reach a final verdict on the motor learning ability of children with DCD, both phases of motor skill learning need to tested, something that none of the abovementioned studies did (most of them only tested the first learning stage). As a result, none of them provided clear information on motor learning in DCD or a basis on which to conclude whether or not motor learning is impaired. Only two recent studies have tested both stages of motor learning using a perceptuomotor adaptation or sequence task [17, 33]. Both supported the idea that implicit and explicit motor learning is preserved in children with DCD. Lejeune et al. [17] explored the steps of motor learning in children with and without DCD, using a perceptuomotor adaptation task in which children use a computer mouse to "catch" and move a stimulus with normal or inverted modes. They found similar rates of learning, consolidation, and transfer in both groups, although the performances of the children with DCD were slower than those of their TD peers. Using a finger sequence tapping task (executing a predefined sequence of tapping finger on a response pad), Biotteau et al. [33] investigated procedural learning at the prelearning stage, after 2 weeks of training, and in a posttraining dual-task condition. The authors found that children with DCD were just as capable as the others of learning a sequence of movements until they were automatized, but performed more poorly: they are initially less gifted and have slower rates of learning. All in all, these studies provide evidence that the ability to learn either implicitly or explicitly is efficient in children with DCD. They are usually slower and less accurate than their peers and probably need more time and more training to reach an appropriate level of performance (especially for complex motor learning), but they are still able to engage in an effective process of motor learning that is sufficient to ensure retention, automatization, and transfer.

\section{What About Motor Learning in more Ecological Tasks?}

Some studies have assessed motor learning via a computerbased game or virtual reality. More ecological and closer to children's natural activities in daily life, these studies focused on the process of acquiring a complex but real motor skill (hockey slap shot, ski slalom, etc.) [35, 36] and required complex whole-body movements over a long period of learning (several weeks or months) with multiple repeated trials. Even if such studies remain remarkably rare in DCD, recent interest in intervention programs has resulted in a modest increase [34, 36, 39-41]. These ecological motor learning tasks, which are very different from tasks requiring a series of key presses, provide a vision that is both congruent and complementary to earlier studies.

Three important findings in particular deserve to be highlighted. First, the learning rate of children with DCD seems to be slower than that of TD children, especially for short-term motor learning [34]. DCD therefore appears to be characterized by the delayed acquisition and learning of motor skills: to reach an appropriate level of performance, they need more time.

Second in some but not all conditions [36], children with DCD appear to learn differently from TD children [34], using different strategies to improve performance and motor learning. In particular, even if they receive the same instructions and feedback, children with DCD seem to persist more in their less efficient initial strategy (for example, misordering elements of a sequence or performing poorer on action planning) [42] and are loath to adapt to a new and more efficient one, contrary to what is seen in TD children.

Third, all these studies support the view that long-term motor learning in children with DCD seems preserved. For instance, when Smits-Engelsman et al. [36] analyzed 100 trials of a ski slalom game, they found that children with DCD did not differ from TD children in their learning rate, had similar levels of retention, and showed evidence of the spontaneous transfer of learning.

Taken together, these studies provide evidence that children with DCD present certain limitations in motor learning but do not have a learning deficit as such: they can acquire and retain skills, and transfer them to other tasks. In other words, with proper training, they can increase their motor performance and improve their learning, even if they are sometimes (probably depending on task difficulty or complexity) slower than TD children, use less efficient strategies, need more practice, and do not take constraints or feedback into account to adapt their learning strategy. Slower and less efficient means leads to acquired skills less readily, which perhaps influences their motivation to persist with practice (that may be related, in part, to a motor learning issue).

\section{Discussion}

DCD does not imply an inability to learn motor skills. Children may be less efficient and probably need more time and practice to learn and reach a satisfactory level of 
performance, but they are still able to learn. However, the question of why these children have difficulty learning motor skills remains unanswered.

\section{Motor Learning Deficit: a Lack of Sufficient Practice?}

Consistent with field observations of children with DCD going about their everyday lives, studies point to a potential motor learning deficit (slow learning in particular), but this is not incompatible with motor learning. In this context, how can we explain such impairment?

Some authors have recently come up with a reliable explanation for this poor motor learning, based on the assumption that it is generated by a lack of experience or well documented in the activity-deficit hypothesis [18, 43]. Children with DCD are self-conscious and well aware of their poor motor skills [43]. Consequently, as self-perception is an important mediator of participation in physical activity, persistent failure and difficulty performing motor-based activities leads to a loss of motivation to take part in physical activity [44]. Children with DCD therefore tend to reduce their motor occupation, adopt sedentary lifestyles [45], and gradually reduce their motor engagement [46], eventually spending significantly less time participating in physical activity than children without DCD [47]. Consequently, lack of opportunity prevents them from improving their motor skills, and a vicious and negative cycle begins. Their motor impairments may limit their performance in activities of daily living, play, leisure, and academic skills. Limited performances lead to a lack of motivation and to lower motor involvement, while they probably need more time for learning. This, in turn, may result in further delay in the acquisition of new skills and hinder their ability to learn efficiently, as first postulated by Bouffard et al. [48].

\section{From Behavioral Studies to Clinical Intervention}

Children with DCD are able to learn motor skills but have greater difficulty doing so than their peers. In particular, in the absence of any intervention (help from parents or intervention strategies), they generally fail to improve their motor skill learning. To help children with DCD learn motor skills, three important aspects need to be highlighted.

First, the amount of experience is often regarded as the most important determinant of improvements in motor skill learning [18]. This inevitably leads us to talk about time on task, which is an important ingredient of treatment success when it comes to improving motor skill learning in children. As we have said before, children with DCD tend to take longer to learn motor skills. Thus, only practicing motor skills in daily life or during intervention sessions is probably not enough to increase performances. In order to improve motor learning, children with DCD need to practice both during interventions and at home, to ensure treatment effectiveness and promote transfer of what has been learned to daily life.

Second, it seems to be equally important to enhance children's motivation through, for example, selection of learning goals. To do so, it is important to take account of the everyday ecological context, preserved abilities (explicit motor teaching or implicit learning), and personal motivations (giving them opportunities to practice their motor skills through playing games that provide enjoyment $[36,40])$.

Third, we know that TD children learn motor skills either implicitly or explicitly, by observing and imitating other children and adults and/or through trial and error. These foundation skills and innate abilities, which are quite important in the motor learning process, are reduced in children with DCD. In particular, one key characteristic of motor learning in children with DCD is a reduced ability to learn from their mistakes, resulting in the persistence of incorrect strategies [42]. One way of helping affected children would therefore be to assist them in monitoring their performances, detecting or identifying sources of errors, and, of course, correcting them as taskspecific self-instruction intervention used to improve handwriting ability [49].

\section{Final Notes}

The aim of the present study was to review and summarize what we currently know about motor learning in DCD. In particular, we sought to gauge the extent to which motor learning may be impaired in individuals with DCD. Are they only slower, only less accurate, less efficient or impaired?

There is little published research on motor learning in children with DCD, and very few studies have attempted to assess both stages of motor learning in order to address the process of motor learning in its entirety. Our analysis of this literature indicates that children with DCD can learn motor skills, can improve their motor performance through repetition, and are able to adjust their use of motor procedures over a short period of training, regardless of the task paradigm used (motor sequence learning, motor adaptation tasks, or learning by practice) and the type of learning (implicit or explicit). They can achieve shortterm learning [19], long-term retention, and automatization [33, $36]$ and even show evidence of transfer to other tasks $[17,36]$. Children with DCD are therefore able to learn a motor skill and benefit from training based on repetition, even if some adjustments are needed. Finally, at a time of growing interest in comorbidity in neurodevelopmental disorders, our analysis suggests that even children with DCD and a comorbid disorder $[19,33]$ can improve their learning ability through training.

Nonetheless, it is indisputable that the learning issue is one of degree between DCD and non-DCD and important differences in the learning pattern across tasks must be highlighted in this conclusion. More specifically, several studies have reported that children with DCD tend to take longer to learn 
motor skills: their motor learning often starts from a lower level and is slower, awkward, and inaccurate. Additionally, whereas they seem to be just as able as others to learn simple and intermediate motor tasks, they display learning important difficulties for more complex motor tasks [30]. To date, neuroimaging studies are still too few in number in DCD to define the neural networks that might be implicated in such learning differences, even if the first results support parietal, cerebellum [29], and dorsolateral prefrontal cortex [50] dysfunctions. But the day-to-day implications of reduced learning capacity for acquisition of functional skills are obviously major, whether for leisure activities, education, instruction, or therapy.

Overall, research findings suggest that while DCD does not imply an inability to learn motor skills, children with DCD have a poor natural disposition to learn motor skills or develop effective learning strategies. These results need, of course, to be confirmed with larger and more diverse samples, in particular taking the issue of comorbidity more rigorously into account. Functional and structural neuroimaging studies should therefore be used to confirm (or contest) these behavioral data and especially to highlight brain differences.

Acknowledgments This work was promoted by the University Hospital of Toulouse-Purpan for regulatory and ethic submission (AOL No. 137004 03) and was supported by a grant from The French National Research Agency (ANR-13-APPR-0010-01). The authors thank Elizabeth Portier for her careful checking of the English language and the reviewers for their constructive comments.

\section{Compliance with Ethical Standards}

Conflict of Interest Maëlle Biotteau, Yves Chaix, and Jean-Michel Albaret declare that they have no conflict of interest.

Human and Animal Rights and Informed Consent This article does not contain any studies with human or animal subjects performed by any of the authors.

\section{References}

1. American Psychiatric Association. Diagnostic and statistical manual of mental disorders. 5th ed. Washington: Author; 2013.

2. Zwicker J, Harris S, Klassen A. Quality of life domains affected in children with developmental coordination disorder: a systematic review. Child Care Health Dev. 2012;39:562-80.

3. Bo J, Colbert A, Lee CM, Schaffert J, Oswald K, Neill R. Examining the relationship between motor assessments and handwriting consistency in children with and without probable developmental coordination disorder. Res Dev Disabil. 2014. doi:10.1016/ j.ridd.2014.04.027.

4. Zwicker JG, Harris SR, Klassen AF. Quality of life domains affected in children with developmental coordination disorder: a systematic review. Child Care Health Dev. 2013. doi:10.1111/j.1365-2214. 2012.01379.x.

5. Cousins M, Smyth MM. Developmental coordination impairments in adulthood. Hum Mov Sci. 2003;22(4-5):433-59.
6. Gomez A, Sirigu A. Developmental coordination disorder: core sensori-motor deficits, neurobiology and etiology. Neuropsychologia. 2015;79(Part B):272-87. doi:10.1016/j. neuropsychologia.2015.09.032.

7. Schmidt RA, Lee TD. Motor learning and performance. 5th ed. Champaign: Human Kinetics; 2014.

8. Fitts PM. Perceptual-motor skill learning. In: Melton AW, editor. Categories of human learning. New York: Academic; 1964. p. 243 85.

9. Doyon J, Benali H. Reorganization and plasticity in the adult brain during learning of motor skills. Curr Opin Neurobiol. 2005;15(2): 161-7.

10. Seidler RD. Neural correlates of motor learning, transfer of learning, and learning to learn. Exerc Sport Sci Rev. 2010. doi:10.1097/JES. 0b013e3181c5cce7.

11. Magill RA. Motor learning and control: concepts and applications. 9th ed. New York: McGraw-Hill; 2011.

12. Wilson PH, Ruddock S, Smits-Engelsman B, Polatajko H, Blank R. Understanding performance deficits in developmental coordination disorder: a meta-analysis of recent research. Dev Med Child Neurol. 2013. doi:10.1111/j.1469-8749.2012.04436.x.

13. Nissen MJ, Bullemer P. Attentional requirements of learning: evidence from performance measures. Cogn Psychol. 1987;19:1-32.

14. Pine ZM, Krakauer JW, Gordon J, Ghez C. Learning of scaling factors and reference axes for reaching movements. Neuroreport. 1996;7:2357-61.

15. Martin TA, Keating JG, Goodkin HP, Bastian AJ, Thach WT. Throwing while looking through prisms. 1. Focal olivocerebellar lesions impair adaptation. Brain. 1996;119:1183-98.

16. Izawa J, Criscimagna-Hemminger SE, Shadmehr R. Cerebellar contributions to reach adaptation and learning sensory consequences of action. J Neurosci. 2012;32(12):4230-9.

17. Lejeune C, Wansard M, Geurten M, Meulemans T. Procedural learning, consolidation, and transfer of a new skill in developmental coordination disorder. Child Neuropsychol. 2016. doi:10.1080/ 09297049.2014.988608.

18. Schoemaker MM, Smits-Engelsman BCM. Is treating motor problems in DCD just a matter of practice and more practice? Curr Dev Disord Rep. 2015. doi:10.1007/s40474-015-0045-7.

19. Magallón S, Crespo-Eguílaz N, Narbona J. Procedural learning in children with developmental coordination, reading, and attention disorders. J Child Neurol. 2015. doi:10.1177/0883073815572227.

20. Hands BP, Larkin D. Developmental coordination disorder: a discrete disability. N Z J Disabil Stud. 2001;9:93-105.

21. Ferguson GD, Jelsma J, Versfeld P, Smits-Engelsman BCM. Using the ICF framework to explore the multiple interacting factors associated with developmental coordination disorder. Curr Dev Disord Rep. 2014. doi:10.1007/s40474-014-0013-7.

22. Camden C, Wilson B, Kirby A, Sugden D, Missiuna C. Best practice principles for management of children with developmental coordination disorder (DCD): results of a scoping review. Child Care Health Dev. 2015. doi:10.1111/cch.12128.

23. Lejeune $\mathrm{C}$, Catale $\mathrm{C}$, Willems $\mathrm{S}$, Meulemans $\mathrm{T}$. Intact procedural motor sequence learning in developmental coordination disorder. Res Dev Disabil. 2013. doi:10.1016/j.ridd.2013.03.017.

24. Wilson PH, Maruff P, Lum J. Procedural learning in children with developmental coordination disorder. Hum Mov Sci. 2003;22(4-5): 515-26.

25. Cantin N, Polatajko HJ, Thach WT, Jaglal S. Developmental coordination disorder: exploration of a cerebellar hypothesis. Hum Mov Sci. 2007;26(3):491-509.

26. Brookes RL, Nicolson RI, Fawcett AJ. Prisms throw light on developmental disorders. Neuropsychologia. 2007;45:1921-30.

27. Kagerer FA, Bo J, Contreras-Vidal JL, Clark JE. Visuomotor adaptation in children with developmental coordination disorder. Mot Control. 2004;8(4):450-60. 
28. Kagerer FA, Contreras-Vidal JL, Bo J, Clark JE. Abrupt, but not gradual visuomotor distortion facilitates adaptation in children with developmental coordination disorder. Hum Mov Sci. 2006;25:622-33.

29. Zwicker JG, Missiuna C, Harris SR, Boyd LA. Brain activation associated with motor skill practice in children with developmental coordination disorder: an fMRI study. Int J Dev Neurosci. 2011;29(2):145-52.

30. Cantin N, Ryan J, Polatajko HJ. Impact of task difficulty and motor ability on visual-motor task performance of children with and without developmental coordination disorder. Hum Mov Sci. 2014. doi: 10.1016/j.humov.2014.02.006.

31. Missiuna C. Motor skill acquisition in children with developmental coordination disorder. Adapt Phys Act Q. 1994;11:214-35.

32. Candler C, Meeuwsen H. Implicit learning in children with and without developmental coordination disorder. Am J Occup Ther. 2002;56:429-35.

33. Biotteau M, Chaix Y, Albaret J-M. Procedural learning and automatization process in children with developmental coordination disorder and/or developmental dyslexia. Hum Mov Sci. 2015. doi:10. 1016/j.humov.2015.07.005.

34. Jelsma D, Ferguson GD, Smits-Engelsman BCM, Geuze RH. Short-term motor learning of dynamic balance control in children with probable developmental coordination disorder. Res Dev Disabil. 2015. doi:10.1016/j.ridd.2014.12.027.

35. Marchiori GE, Wall AE, Bedingfield EW. Kinematic analysis of skill acquisition in physically awkward boys. Adapt Phys Act Q. 1987;4:304-15.

36. Smits-Engelsman BCM, Jelsma LD, Ferguson GD, Geuze RH. Motor learning: an analysis of 100 trials of a ski slalom game in children with and without developmental coordination disorder. PLoS ONE. 2015. doi:10.1371/journal.pone.0140470.

37. Gheysen F, Van Waelvelde H, Fias W. Impaired visuo-motor sequence learning in developmental coordination disorder. Res Dev Disabil. 2011;32:749-56.

38. Guadagnoli MA, Lee TD. Challenge point. A framework for conceptualizing the effects of various practice conditions in motor learning. J Motor Behav. 2004;36:212-24.

39. Mombarg R, Jelsma D, Hartman E. Effect of Wii-intervention on balance of children with poor motor performance. Res Dev Disabil. 2013;34(9):2996-3003. doi:10.1016/j.ridd.2013.06.008.

40. Jelsma D, Geuze RH, Mombarg R, Smits-Engelsman BCM. The impact of Wii Fit intervention on dynamic balance control in children with probable developmental coordination disorder and balance problems. Hum Mov Sci. 2014;33(1):404-18.

41. Hammond J, Jones V, Hill EL, Green D, Male I. An investigation of the impact of regular use of the Wii Fit to improve motor and psychosocial outcomes in children with movement difficulties: a pilot study. Child Care Health Dev. 2014. doi:10.1111/cch.12029.

42. Goodgold-Edwards SA, Cermak SA. Integrating motor control and motor learning with neuropsychological perspectives on apraxia and developmental dyspraxia. Am J Occup Ther. 1990;44(5):431-9.

43. Green D, Lingam R, Mattocks C, Riddoch C, Ness A, Emond A. The risk of reduced physical activity in children with probable developmental coordination disorder: a prospective longitudinal study. Res Dev Disabil. 2011;32(4):1332-42.

44. Cairney J, Hay JA, Faught BE, Wade TJ, Corna L, Flouris A. Developmental coordination disorder, generalized self-efficacy toward physical activity, and participation in organized and free play activities. J Pediatr. 2005;147(4):515-20.

45. Poulsen AA, Ziviani JM, Cuskelly M. Perceived freedom in leisure and physical co-ordination ability: impact on out-of-school activity participation and life satisfaction. Child Care Health Dev. 2007;33(4):432-40.

46. Rivilis I, Hay J, Cairney J, Klentrou P, Liu J, Faught BE. Physical activity and fitness in children with developmental coordination disorder: a systematic review. Res Dev Disabil. 2011;32(3):894-910.

47. Cairney J, Hay JA, Veldhuizen S, Missiuna C, Faught BE. Developmental coordination disorder, sex, and activity deficit over time: a longitudinal analysis of participation trajectories in children with and without coordination difficulties. Dev Med Child Neurol. 2010. doi:10.1111/j.1469-8749.2009.03520.x.

48. Bouffard M, Watkinson EJ, Thompson LP, Causgrove Dunn JL, Romanow SKE. A test of the activity deficit hypothesis with children with movement difficulties. Adapt Phys Act Q. 1996;13(1): 61-73.

49. Jongmans MJ, Linthorst-Bakker E, Westenberg Y, Smits-Engelsman BCM. Use of a task-oriented self-instruction method to support children in primary school with poor handwriting quality and speed. Hum Mov Sci. 2003. doi:10.1016/j.humov.2003.09.009.

50. Debrabant J, Gheysen F, Caeyenberghs K, Van Waelvelde H, Vingerhoets G. Neural underpinnings of impaired predictive motor timing in children with developmental coordination disorder. Res Dev Disabil. 2013. doi:10.1016/j.ridd.2013.02.008. 